\title{
BUTT WELDING OF ROUND DRIVE BELTS
}

\author{
Krzysztof WAŁĘSA*, Ireneusz MALUJDA*, Krzysztof TALAŚKA*
}

*Faculty of Machines and Transportation, Chair of Basics of Machine Design, Poznań University of Technology, ul. Piotrowo 3, 60-965 Poznań, Poland

kwalesa@poczta.fm, ireneusz.malujda@put.poznan.pl, krzysztof.talaska@put.poznan.pl

received 27 September 2017, revised 8 June 2018, accepted 12 June 2018

\begin{abstract}
The on-going rapid development of industry encourages development of new production technologies and designing of machines that use inventive mechanical engineering solutions, a big demand for parts of such machines being a natural consequence. Polymeric power transmission belts are a good example of that. This paper proposes an improvement in the process of production of such belting. Their production includes cutting to length and splicing of elastic round belts to obtain endless belts of the specified length. This is the key phase of the whole production process. A number of splicing methods are available using different physical phenomena. One of them is butt welding technique. In this process heat is applied on the material through an additional heating element called the heat platen. The effect depends on several factors, including preparation of the work pieces. Due to its characteristics the process is often carried out by hand. The need for automated manufacturing was created by important factors associated with manufacturing on an industrial scale: cost, time and quality. The proposed butt welding machine, complete with a control system is an answer to this need. The practical benefits include improved repeatability of splices, time savings and less work load for the operator.
\end{abstract}

Key words: Splicing, Welding, Power Transmission Belts, Conveyor Belts

\section{INTRODUCTION}

Machines and equipment used in industrial applications are becoming more and more complicated. There are multiple factors responsible for that.

The technological progress results in an increasing variety of products designed to match various needs of people. This results in an increasing variety of machines that are needed to produce them. Consequently, the machines and equipment are becoming more and more complicated. Improvement of the process efficiency is a desired result.

Note also that automated equipment can perform a sequence of tasks repeatedly and without needing further action of the operative and thus it can successfully replace man in the process of production. As an additional benefit, relieving the operator from burdensome tasks promotes a better and safer work environment. Moreover, a higher accuracy and repeatability of finished product parameters has a beneficial effect on the production quality.

Another important factor responsible for increasing complexity of industrial machines are the cost efficiency and reduction criteria. Reliability and simplicity of operation are closely related to them.

This created a need for fully automatic machines in which power is transmitted through round, polyurethane belts (Domek and Malujda, 2007). Belts of this type are widely used for transmission of power in machines such as rolling mills, roller conveyors, sorting lines and conveying belts. Their main task is transmission of power between the subsequent roller assemblies or processing stations. Enjoying a very wide range application in many industries, including in particular light industry (for example in papermaking or plastic production machines) such belt is in high demand. They are used in difficult conditions, i.e. in low and high temperatures, environments susceptible to electrostatic discharge and in food or medical industries (Domek et al., 2016). What is more, like in gear with timing belt, round belts are subjected to action of lots of forces. Circumferential, pre-tension, friction and centrifugal forces, also vibration, cause that there are complex stresses in cross section of belt (Domek and Dudziak, 2011). This provoke high requirements of their quality.

Round polyurethane belts can be used in lots of specialist applying, i.e. in special robotic arm joint mechanism, with two twisted small diameter belts (Inoue et al., 2016). High quality of round polymer belts is required. The main client are manufacturers of machines and beside installation on the delivered machine such belts comes also as a necessary spare part as part of delivery. The demand for such belts reaches hundreds of thousands of pieces.

All the above-mentioned factors have created the need for automation of the splicing process during production. This can be obtained by designing machines performing the tasks which so far had to be done by hand. The desired effect is to develop the process of splicing with considerably limited involvement of humans to relieve the operative from no longer necessary work and to ensure functionality of the designed automatic splicing system.

These were the assumptions for the research project whose results are described herein. This paper describes a proposed mechatronic device enabling automation of the belt splicing process. Heat platen butt welding technique was chosen as a well-proven, widely accepted splicing method, simple and economical. In addition this type of bonding technique, allow to reach high strength joints (Amanat et al., 2010). The engineering work has covered both mechanical and control aspects. 


\section{SPECIFIC FEATURES OF THE DRIVE BELTS MANUFACTURING PROCESS}

Welding of belts section is one of the key steps in the manufacturing process. A number of factors must be considered as part of the engineering work to ensure that the process is performed as desired. Quality of the splicing directly affects the quality of the manufacturing process as a whole. It is important to recognise characteristic processing stages. As important are the specific parameters of the material used in production. Both the procedure and the welding parameters must be defined according to all these factors.

\subsection{Manufacturing process}

Polyurethane power transmission belts are produced from round cords, solid or hollow. The cord section is wound around and joined permanently to obtain the specified circumferential length. This length can vary over a wide range depending on the installation requirements, generally from a few dozen millimetres to a few metres. The belts are manufactured from solid or hollow round cords (belting) of thermoplastic polyurethane which is a material having specific properties. Two methods are used in production of polyurethane belting: extrusion and injection moulding (Sikora, 1993). Diameters of such intermediate products are generally in the range from a few to over a dozen millimetres (Behabelt, 2015).

These intermediate products are usually supplied in quite long sections which is typical of the process used in their production It is not convenient from the point of view of storage and transport. The cord material features elasticity, shape memory and specific allowable bending radius. As a measure to cope with this inconvenience the material is factory wound on spools (rolls) holding between a few dozen to a few hundred metres of cord (Behabelt, 2015).

The next stage is final processing comprising the following steps (Fig. 1):

1. Unwinding of belting from spool and cutting to length

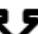

2. Aligment of both ends in relation to each other

\section{5}

\section{Splicing}

Y

4. Quality control

Fig. 1. Polyurethane belt production flow chart

In the first step the cord is unwound from the spool and cut to length (1). This length equals the finished product circumference plus welding allowances. The objective is to obtain the effective length of the finished product which is equal to the circumference measured along the axis of symmetry of the cord (Fig. 2). The cut must be done perpendicular to the axis of symmetry of the cord (Fig. 3). This will provide matching ends, important in further processing.

Next the two ends of the cord are aligned in relation to each other and brought together by force $F$. It is critical to ensure prop- er alignment before welding starts (Fig. 3). This is usually ensured by guiding the two ends with axially aligned guides.

The final product can be formed to shapes other than circular, for example ellipsoidal or any other looped shape, as long as the minimum bend radius is maintained. Its value is most often given in the data sheets by specifying the minimum diameter of roll around which the belt can be routed.

The next step is splicing itself. The parameters of this step are critical to the quality of finished product.

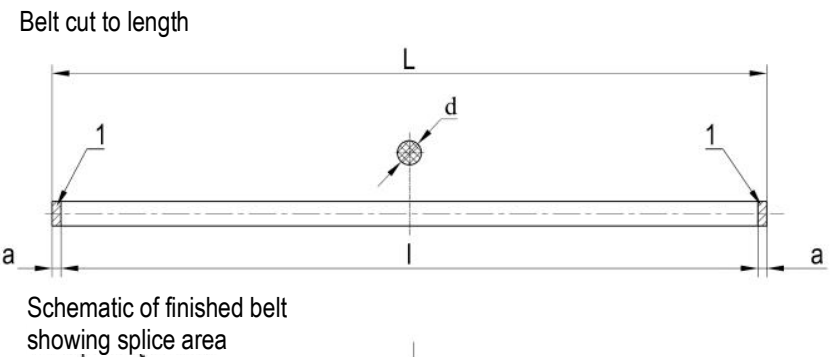

showing splice area

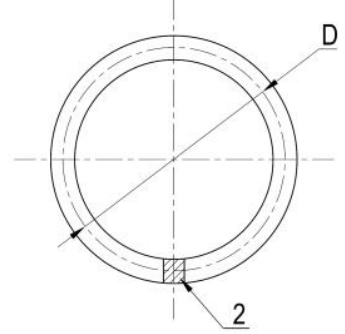

Fig. 2. Dimensional relationships of round belts wound in a circular shape: $L$ - total (cutting) length, $I$ - belt length (circumference after splicing), a - splicing allowance, $\mathrm{d}$ - belt diameter, $\mathrm{D}$ - diameter of the ring obtained from the cord section, 1 - extent of splicing allowances, 2 - splice area

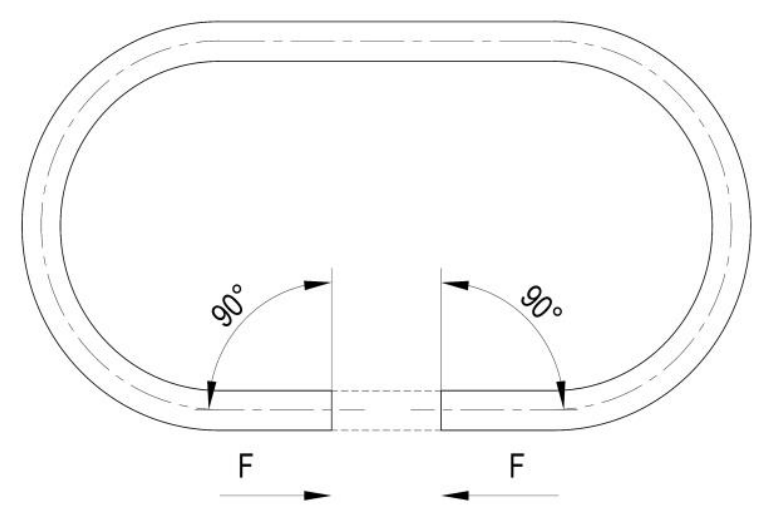

Fig. 3. Schematic drawing showing alignment before splicing: $F$ - force required to bring together the two ends of cord to be joined

In the final step the product is removed from machine and a quality check is carried out. The inspection should cover:

- dimensions in the splicing area - to be checked against specifications (seam diameter should correspond to the thickness of undisturbed part of material),

- axial alignment of the two ends across the splice and alignment of the two horizontal faces during welding,

- welding quality, that is full bonding over the whole thickness.

Any deviation from the above requirements would affect the belt performance, manifested for example by vibrations in power transmission systems. 


\subsection{Joining material properties}

According the design assumptions the material to be joined is polyurethane cord. Polyurethane is one of thermoplastic material, with some of elastomer features.

What is specific about polyurethane is that depending on the chemical composition it can be classified as purely thermoplastic or thermoplastic/elastomeric material. Its physical and chemical properties depend on its chemical composition, internal structure and molecular weight (Żuchowska, 2000).

Polyurethanes have segmental (block) structure. Their hydrocarbon chain is built of alternating flexible (methylene, ester or ether) and rigid (urea, urethane, aromatic) blocks (Fig. 4). The hard blocks are responsible for the strength performance and soft ones improve the deformation capacity of the material (Puszka, 2006). These domains do not intermix and make up two-phase heterogenic structure. The flexible polyurethane varieties contain between $60 \%$ and $80 \%$ of soft blocks. They are generally elastic and easily deformable. The other domain, made up of hard blocks is responsible for mechanical strength (Żuchowska, 2000).

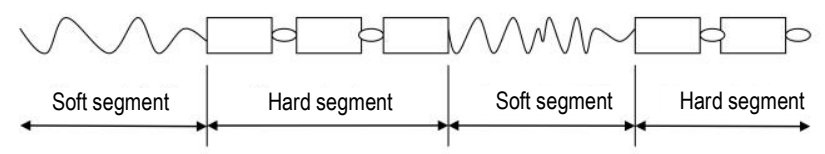

Fig. 4. Example sequence of blocks in polyurethane (Puszka, 2006)

The polyurethane variety used for production of belts is classified in the group of thermoplastic elastomers. They are a mixture of amorphous and crystalline regions.

As a result, polyurethane combines the properties of the two groups. The crystalline regions are responsible for the high strength parameters, clear-cut phase transition temperatures and resistance to chemical compounds. Amorphous regions on their part are responsible for plastic behaviour of the material (Ashby, Jones, 1996). A specific feature of polyurethane, distinguishing it from other plastics, is its behaviour under the effect of higher temperatures. On the macroscopic scale it is manifested by properties typical of elastomers up to the temperature of ca. $100^{\circ} \mathrm{C}$ which is followed by softening typical of thermoplastic materials when heated above that limit (Ciszewski, Radomski, 1989). This is an important characteristic from the point of view of the welding process.

The analysed plastic has a number of physical properties making it a suitable material for production of power transmission belts. Moreover, the physical properties can be modified, givingit universal character. These characteristics include high elastic modulus, high tensile strength and resistance to repeated bending - a most welcome feature for power transmission and conveying belts. Polyurethanes surpass other thermoplastic materials in terms of abrasion and tear resistance, as well as vibration damping performance. Also important, especially in the analysed area of application is the material's insusceptibility to various chemicals. Polyurethanes are resistant to oxidising agents, solutions of acids, lubricants, oils and organic solvents (Madej, Ozimina, 2010). This makes them a suitable material for conveying systems which often involve the presence of various chemical that can be harmful to other engineering materials.

However, it is not possible to precisely determine the properties of polyurethanes without detailed empirical studies. According to the review of available literature the upper limit of temperature resistance ranges between $80^{\circ} \mathrm{C}$ and $120^{\circ} \mathrm{C}$ (Madej, Ozimina, 2010). The tensile strength in normal operating conditions can be assumed in the range from $20 \mathrm{MPa}$ to $70 \mathrm{MPa}$. Breaking failure occurs at $200-800 \%$ elongation. Shore A hardness ranges between $35^{\circ}$ and $98^{\circ}$ (Żuchowska, 2000).

Both thermal and rheological properties must be considered in analysing the process of welding polyurethane belting. When analysing the influence of temperature it is important to consider the melt volume-flow rate (MFR). This characteristic is important for the welding process efficiency beside other key parameters which are: density, softening point and thermal conductivity of the material. As the value of MFR increases the viscosity of the material decreases, reducing the internal cohesion forces. As a result, partially melted material tends to escape from the splicing area under the force of gravity. MFR decreases with the increase of molecular weight (Żuchowska, 2000).

All these characteristics must be taken into account when designing polyurethane welding machine. Their values should define the welding process parameters.

\section{HOT PLATE WELDING}

Hot plate welding process is one of the polyurethane direct bonding method (Amanat et al., 2010). It uses the thermal action in the volume of material. In hot plate welding process the joined pieces are heated up by the heat transferred from the heating element to the mating surfaces. This is performed with a specially mounted heater unit comprising a hot plate which is inserted between the belting ends (Fig. 5). The belt ends are heated up as they are pressed against the platen which leads to softening and partial melting of the material in the contact region.

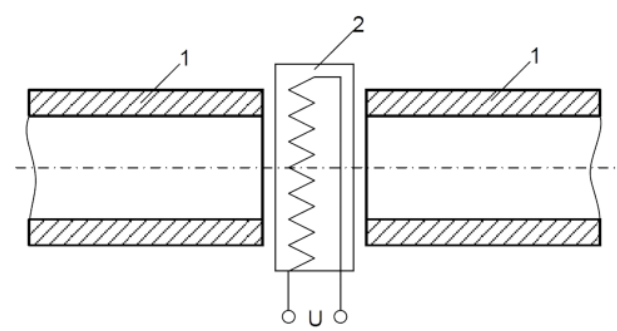

Fig. 5. Butt welding of polymer cords (Sikora, 1993):

1 - pieces to be joined, 2 - hot plate, $U$ - supply voltage

The hot plate shape and power supply parameters should be appropriate to the type of pieces to be joined. The surface of hot plates is always coated with a non-stick material. If the working temperature does not exceed $200^{\circ} \mathrm{C}$, teflon with the thermal resistance of $270^{\circ} \mathrm{C}$ can fit the purpose. For higher working temperatures the heat platens made of $\mathrm{Al}-\mathrm{Cu}$ alloy which can withstand temperatures up to $350^{\circ} \mathrm{C}$ are used. The purpose is to prevent adhesion, and stick of plastic to the heating surface (Klimpel, 1999). Stick material causes deforming the section of melting polymer, and in consequence some gaps in the bond line (Yousepour, 2004).

Fig. 6 presents the procedure which ensures durable bonding of polyurethane belting with a hot plate welding system. Generally this process it is on heating and pressing against of joining surfaces (Amanat et al., 2010). Using this cycle chart, we can create 
the algorithm of welding process, directly for control system (Rzasinski, 2017).

In the first step the two ends of belting are brought together while maintaining alignment and keeping a gap sufficient for inserting the heated plate. Next the plate is placed between the belting ends. It is important to ensure full contact between the ends and the plate so that the temperature is increased evenly throughout the mating surfaces. The plate should be inserted between the ends when it has reached the working temperature. This ensures controlled heating conditions and shortens the process time.

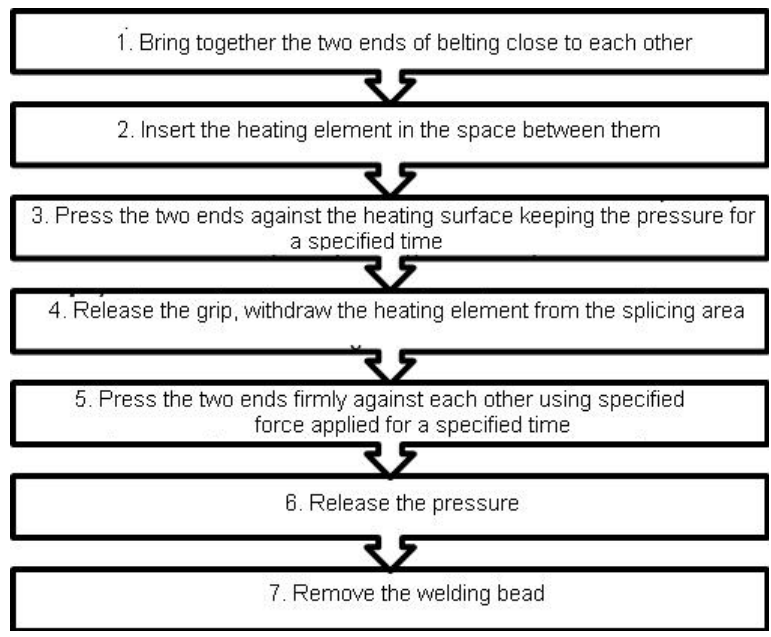

Fig. 6. Butt welding sequence for splicing polyurethane belting

Next the two ends should be pressed against the plate with a specified force. Under the effect of heat transferred to the belting ends the material softens and starts to melt. Additionally polymer chains are activated facilitating chemical reactions associated with linking polymer chains.

In this case heat conduction is an unsteady process. The varying parameters are the coefficient of heat conduction, specific heat, density and viscosity of the heated material. In the case of polyurethane these values strongly depend also on the chemical composition, crystalline structure of the plastic and the sequence of soft and hard blocks.

When the material gets sufficiently softened and partially melted the pressure is released and the belting ends are pulled away from the plate. Next the heater unit is withdrawn from the splicing area.

In the next step the two pieces are pressed against each other. It is important that this step takes place as soon as the plate has been removed from the splicing area. This is to avoid excessive cooling and solidification of melted material. This is the critical step in the whole butt welding process. Chemical reactions take place at that point whereby the macromolecules of melted polymer are connected. This creates a permanent bond between the joined pieces. As soon as the belting ends have been effectively joined pressure can be released. At this point cooling and curing of the joint starts.

Note that the process of butt welding shortens the belting length. Pressing the two ends against each other when the material is soft creates a welding bead that is a ring of material surrounding the joint. The mount of bead material is proportional to the decrease in length of belting. This bead must be removed, most often by cutting, to ensure correct operation of the belt.
Using the cycle chart (Fig. 7) let us review the basic parameters of the butt welding process:

- unit pressure applied on the joined pieces with the maximum values applied in two steps of the welding process. It includes pressure $p_{g}$ applied to level out the surfaces and pressure $p_{z}$ applied during proper welding. Its value ranges generally from $0.05 \mathrm{MPa}$ to $0.1 \mathrm{MPa}$ depending on the type of joined materials (Klimpel, 1999). Decrease of pressure $p_{n}$ in the second phase of heating is related to significant softening of thermoplastic materials under the effect of heat. Excessive pressure applied at this stage would cause excessive amounts of molten material to flow out of the splicing area.

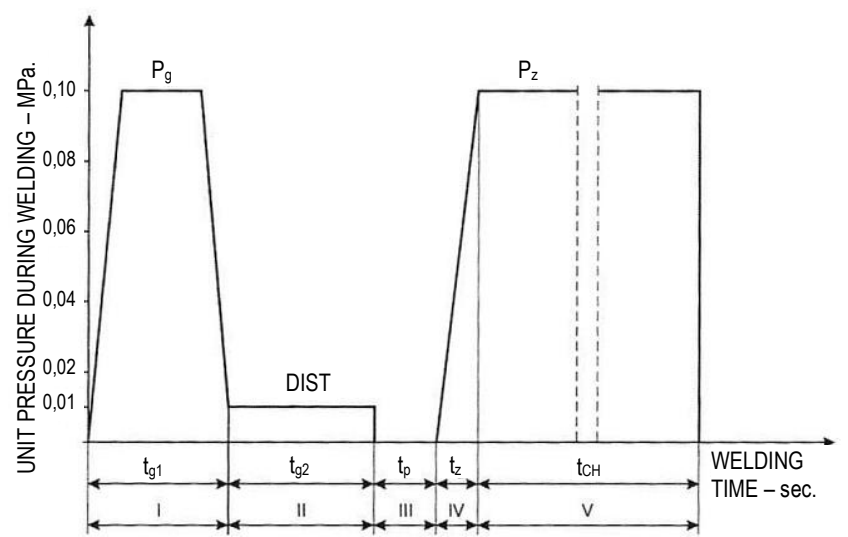

Fig. 7. Cycle chart (cyclogram) of the hot plate welding process (Klimpel, 2000): Stages of the process: I - levelling out the surfaces at high pressure, II - heating up at low pressure, III - hot plate is withdrawn, IV - increase of pressure, $\mathrm{V}$ - welding and cooling of joint; Unit pressure values: $p_{\mathrm{g}}$ - during levelling out the faces, $p_{\mathrm{n}}-$ during heating up, $p_{z}$ - during bulging; Times: $t_{g 1}-$ levelling out the faces, $t_{g 2}$ - heating up, $t_{p}$ - withdrawal of the hot plate, $t_{z}$ - second pressing, $t_{\mathrm{CH}}-$ bulging and cooling of joint

- the cumulative process time, ranging from over a dozen seconds to a few dozen minutes (Cocard, 2009). The levelling out time $t_{g_{1}}$ is usually short and does not exceed a few seconds. In this phase the mating surfaces (faces) are levelled out on the hot plate by partial melting any protrusions. The heating up time $t_{g 2}$ depends on the heated mass and on the thermal properties of the material, such as conductivity and specific heat. It is generally much greater than the time $t_{g 1}$ and can reach up to a few dozen minutes. In special case the whole heating phase $\left(t_{1} 1\right.$ and $\left.t_{2}\right)$ can last more than 60 minutes and depend also on base material's strength (Amancio-Filho, dos Santos, 2009). The hot plate withdrawal time $t_{p}$ is also referred to as pause time must not be longer than a few seconds and preferably should be as short as practicable. The same applies to the pressure increase time $t_{z}$ which, when too long, will unnecessarily increase the input of energy. The last step of the process includes bulging and gradual cooling of the joint. It is usually the longest of all steps with the time $t_{\mathrm{CH}}$ ranging between a few dozen seconds to over a dozen minutes, depending on the external conditions (Klimpel, 1999).

- bulging degree, usually defined by the length reduction during welding. It strongly depends on the maximum pressure applied during welding.

- welding temperature $T_{z}$ which does not equal the heat platen working temperature $T_{\mathrm{p}}$, and is usually lower by a few dozen 
degrees (Fig. 8). For processing partially crystalline polymers, the maximum temperature $T_{\mathrm{z}}$ is usually set ca. $80^{\circ} \mathrm{C}$ to $90^{\circ} \mathrm{C}$ above the melting point. This is different in the case of amorphous polymers for which it is difficult to determine the phase transition temperature and, as such, the welding temperature is taken $150^{\circ} \mathrm{C}-160^{\circ} \mathrm{C}$ above the glass transition temperature (Klimpel, 2000). It is important to choose a temperature that provides sufficient level of softening without causing any harm to the material. The initial degradation temperature of most polyurethane elastomers is ca. $270^{\circ} \mathrm{C}-320^{\circ} \mathrm{C}$, dependent on material type and composition. Exceeding this value cause destroy the material volume in a few stages (Wanqing et al., 2017). On the other hand, in case of some polymers, joint strength increases with welding temperature (Evers et al., 2017). The welding temperature choice is very important issue.

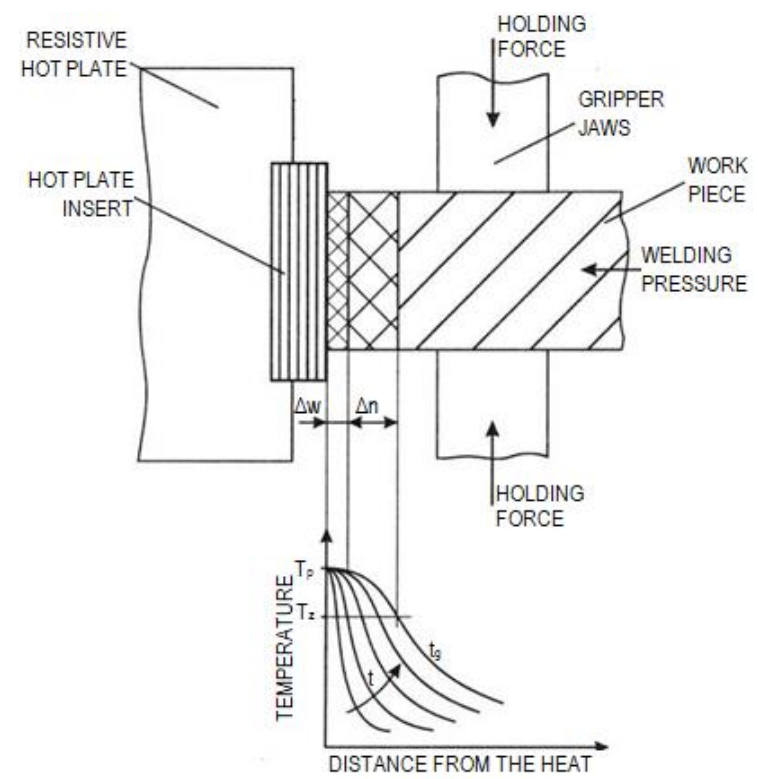

Fig. 8. Schematic of heating an object with a hot plate (Klimpel, 2000): $T_{p}$ - temperature of the hot plate, $T_{z}$ - softening point of welded plastic, $t_{g}$ - specified heating time, $\Delta w$ - allowance for levelling out the surfaces, $\Delta n$ - thickness of layer heated up above the softening point

- levelling out allowance $\Delta w$, that is the length of belting which is partially melted in the initial heating phase with higher pressure applied on the belting in order to level out the faces.

- thickness of layer heated to the temperature required for softening of material $\Delta n$ that defines the amount of material softened during the process of welding. Directly associated with it are the heating time and the level of bulging. It is generally assumed that the thickness of softened layer $\Delta n$ should not be smaller than $30 \%$ of the thickness of the joined material for partially crystalline polymers and $14 \%$ of that thickness for amorphous plastics (Jasiulek, 2006).

Hence, obtaining a welded joint with the specified shape and mechanical properties requires considering a number of factors and specifying many interrelated parameters. In addition, big influence to welding process has pieces preparation. Their smooth surface lead to increasing contact with hot tool and better heat transference (Amoncio-Filho, dos Santos, 2009). When the heating and cooling process is considered, also it should be noted some division in three zone with different impact of temperature.
This phenomenon can be observed in all of the semi - crystalline thermoplastic polymers, so in butt welding of round belts it has some impact to process (Casalino, Ghrobel, 2008). The difficulty of predicting the behaviour of different types materials during the process of welding adds to the complexity of the problem. All the above factors are taken into consideration when formulating the machine design assumptions.

\section{MECHATRONIC DESIGN APPROACH}

\subsection{Mechanical part}

Fig. 9 presents the system for automatic splicing of belts by hot plate welding designed after examining the various factors influencing the butt welding process. The designed system has modular structure.
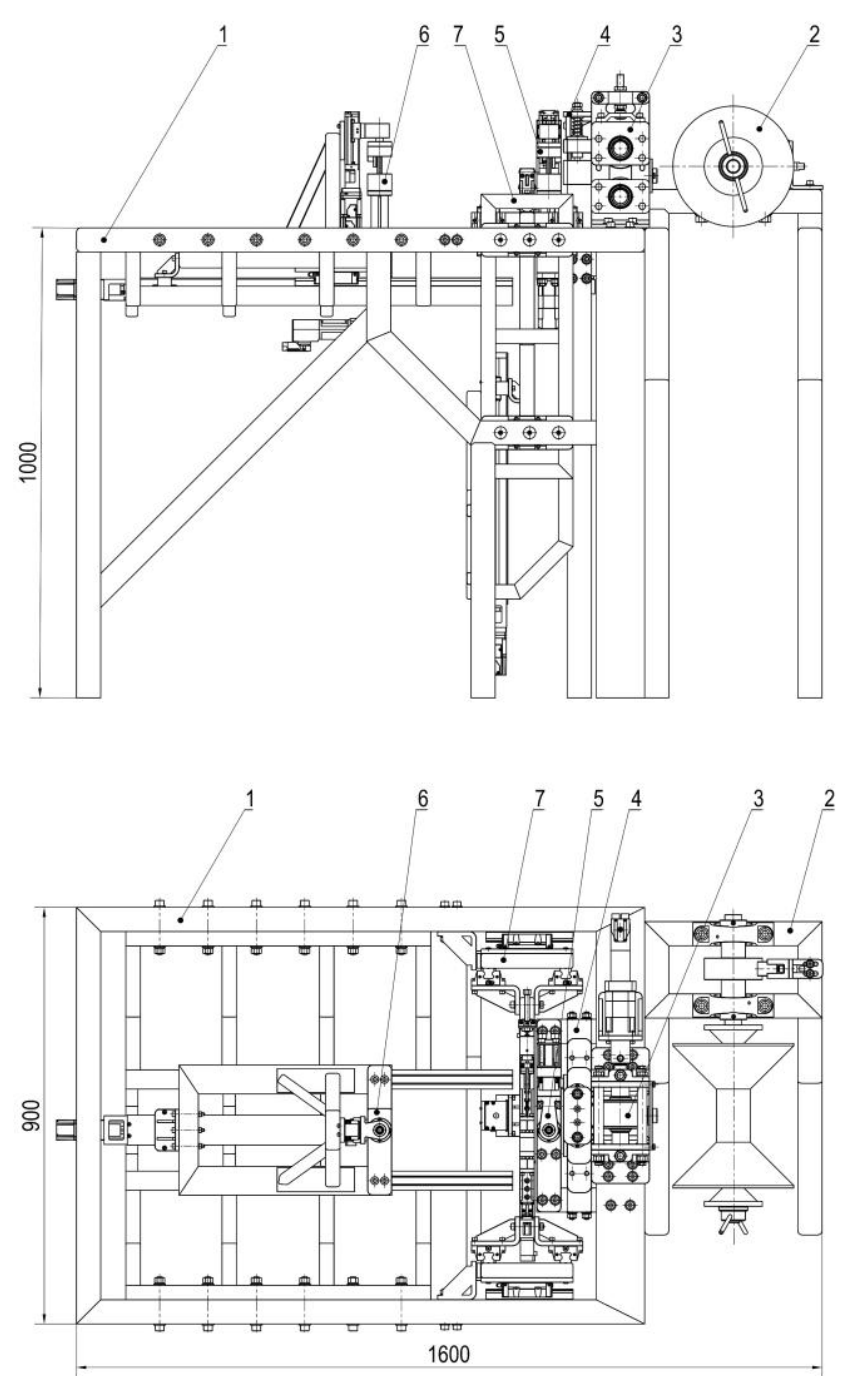

Fig. 9. System for automatic welding of belts: 1 - main frame, 2 - unwind unit, 3 - roll feeder, 4 - shear cutter, 5 - fixed gripper, 6 - sliding gripper, 7 - welding assembly

The main structural component is the main frame (1). Its main function is to combine all the assemblies and keep them at the required distances in relation to each other. 
The first assembly (2) is designed for pulling the cord from the spool. The main function is to unwind only such length that is required for further processing. Uncontrolled unwinding of the spool must be prevented.

The next important assembly is the roll feeder (3). Its primary function is to set the belt in translational motion during the preparatory phase before welding. The cord is moved at a constant speed adjusted to the operating speeds of the subsequent assemblies. An additional function is to measure the length of the unwound cord section. This information is used by the cutting control system to ensure the specified length of the finished belt.

Next the cord is directed to the shear cutter (4) synchronised with the roll feeder.

The fixed gripper assembly (5) is designed to grip one end of belting and position it in three-dimensional space. Its characteristic feature is that it can rotate about its axis and grip the cord through displacement of the gripping parts. It is fixed to the main frame of the machine (1).

The same idea is used in the design of the sliding gripper assembly (6). Its movements are similar to the fixed gripper assembly (5). The difference is that in addition to the movements of the fixed gripper the whole assembly can move in the direction parallel to the cord feed axis. This feature enables producing belts of different lengths and prevents collisions of moving parts during operation.

The two gripper assemblies operate in conjunction. Their main function is to arrange the ends of cord section facing each other just before welding. Moreover, then can move to adjust process parameters as required, including pressure during heating up and welding and shifting to remove the welding bead.

The most important part from the point of view of the overall function of the machine is, of course, the welding assembly (7). It supplies the heat required for softening and partial melting of the work pieces, ensures that the specified geometric parameters are obtained and removes the welding bead from the finished belt.

The design enables carrying out all the operations required to splice the belt to the specified geometric and strength parameters.

In order to understand the overall operation of the machine let us consider the design and operation of its assemblies. These are:

- unwind unit (Fig 10) - pulls the cord from the spool. The assembly is mounted on the main frame (1). The unwind shaft (3) is supported on the frame through bearing assemblies (3). The shaft can freely rotate about its axis. The spool with belting (4) is fitted on the shaft and protected from sliding off with a wing nut (5). Thus the spool rotates together with the shaft. To control the movement the assembly is provided with a drum brake (6) comprising the brake shoe and drum (7) mounted on the shaft with the stopping effected by friction. The brake generates friction moment which stops the spool after the required length has been pulled off. This prevents uncontrolled unwinding of the cord.

- the belt is set in motion by the roll feeder (Fig. 11). The main sub-assembly of the feeder is the powered roll with knurled surface (1) supported on the bearing (4) mounted in the bearing case (3). The back-up roll sub-assembly has a similar design comprising the shaft-mounted plain surface pressure roll (2) supported on the bearing (5) mounted in the case (3). The bearing sub-assembly can be moved and is linked to the roller gap adjustment mechanism (9) which is also fixed to the case (3). It enables pressing down the belting against the powered roll (1) through pressure roll (2) owing to its vertical movement. The roll driving system (1) comprises the servomotor (6) and the planetary gear (7). The feeder case (3) and bracket of the drive system (8) are bolted to the main frame ((1) in Fig. 9) A supplementary element of the system is the cord guide (10) whose task is to feed the cord in the central part of the gap between the feeder rolls.

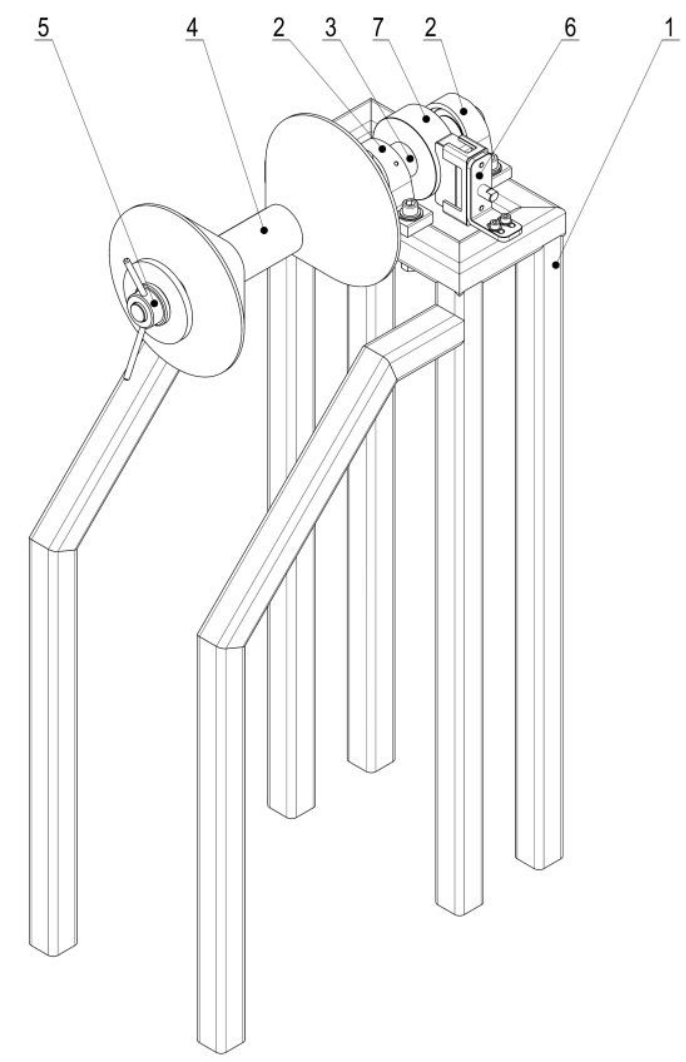

Fig. 10. Unwind unit: 1 - frame, 2 - bearing assemblies, 3 - main shaft, 4 - spool, 5 - securing nut, 6 - drum brake sub-assembly, 7 - brake drum

The roll feeder receives the cord from the unwind unit and moves it to the shear cutter assembly ((2) and (4) in Fig. 9). When servomotor is started (6) the torque is transferred through the planetary gear reducer (7) and through the shaft to the powered roll (1). The cord which is pressed down by the top roll (2) moves without any slipping with the speed of the tangent component of the angular speed of powered roll (1) and in this way it is fed to the subsequent assemblies of the machine. The cord length control is based on the number of rotations of the servomotor (6), geometric parameters of the roll (1) and the reducer gear ratio (7). Upon reaching the preset value the servomotor is stopped. Cord slippage is prevented by the powered roll (1) surface texture and pressure exerted by the pressure roll (2) which ensures reliable length measurement of the cord section delivered for welding.

The cord is cut to length by the shear cutter assembly (Fig. 12). Its support frame is bolted to the main frame ((1) in Fig. 9). It includes the die (5) and the double-acting air cylinder (2). The die has a prismatic groove in which the cord is supported during movement and cutting to length operations. The cord is fed between the prismatic surfaces (5) and the hold-down device (6). After cutting command is received from the control unit the air 
cylinder (2) through the upright guides (3) supported on bearings effects movement of the cutting sub-assembly (4) comprising the cutting blade (knife) and all the required brackets/holders and guides. The cutting sub-assembly (4) moves down into the die (5) thus cutting the cord. The hold-down device (6) is elastically connected to the cutting sub-assembly. Its function is to press down the cord against the die (5) during cutting. This secures the cord in place, ensuring perpendicular cut (in relation to the longitudinal axis of the cord). Owing to the flexible connection between them the shear cutter assembly (4) and hold-down device (6) can move together during cutting operation in which the shear cutter assembly (4) can be lowered to cut through the cord while the hold-down device rests on the cord surface (4). The flexible components, compressed by the down movement of the shear cutter generate the pressure holding down the cord against the die (5).
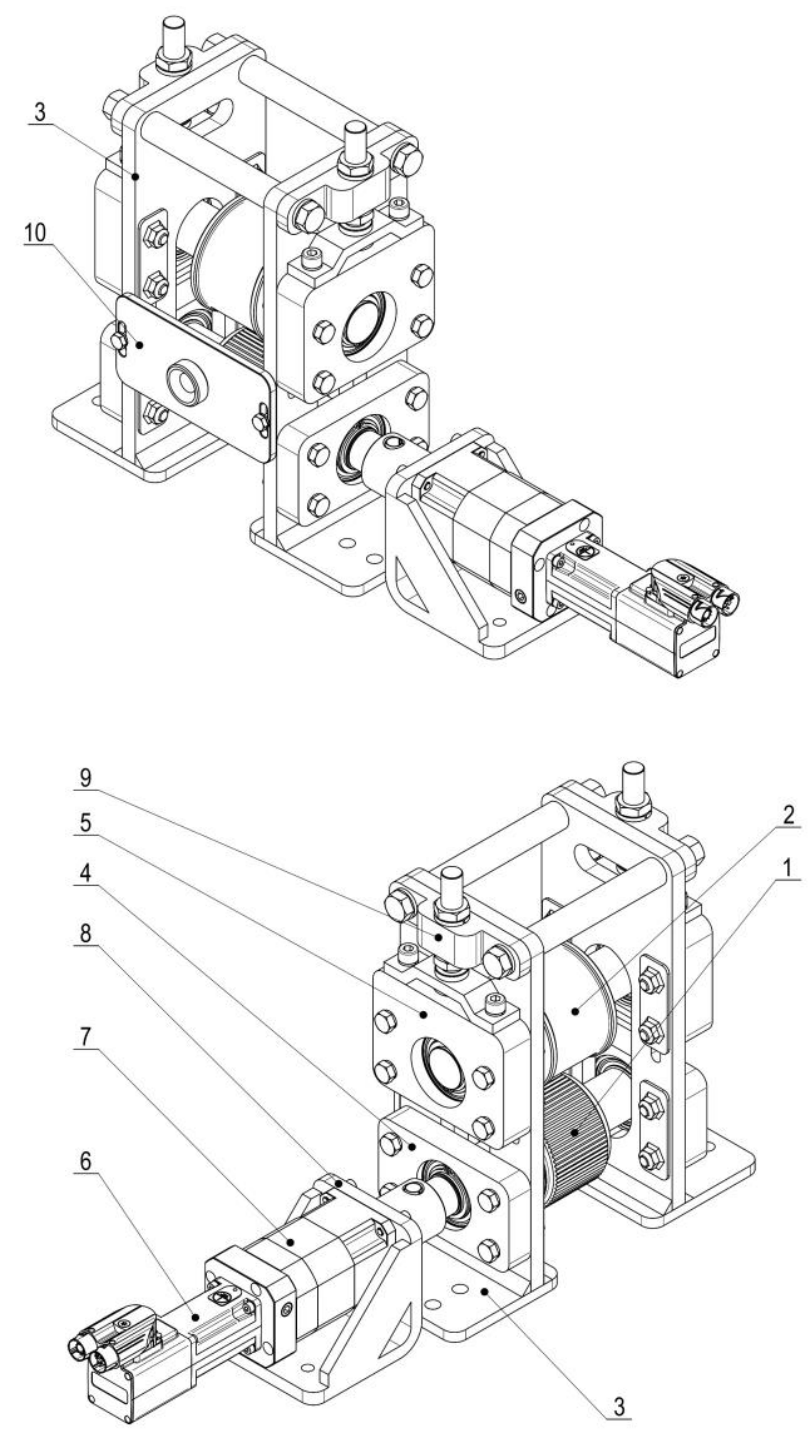

Fig. 11. Roll feeder: 1 - powered roll, 2 - pressure roll, 3 - case, 4 - bearing assembly, 5 - hold-down device bearing system, 6 - servomotor, 7 - planetary gear reducer, 8 - drive system bracket, 9 - hold-down pressure adjustment mechanism, 10 cord guide

The die design enables cutting cords with different diameters without a need for re-tooling and adjusts the cord position during cutting. This facilitates operation and ensures satisfactory degree of perpendicularity of cut in relation to the cord axis.
- the function of the fixed gripper assembly (Fig. 13) is to grab and position one of the ends of the belting section.
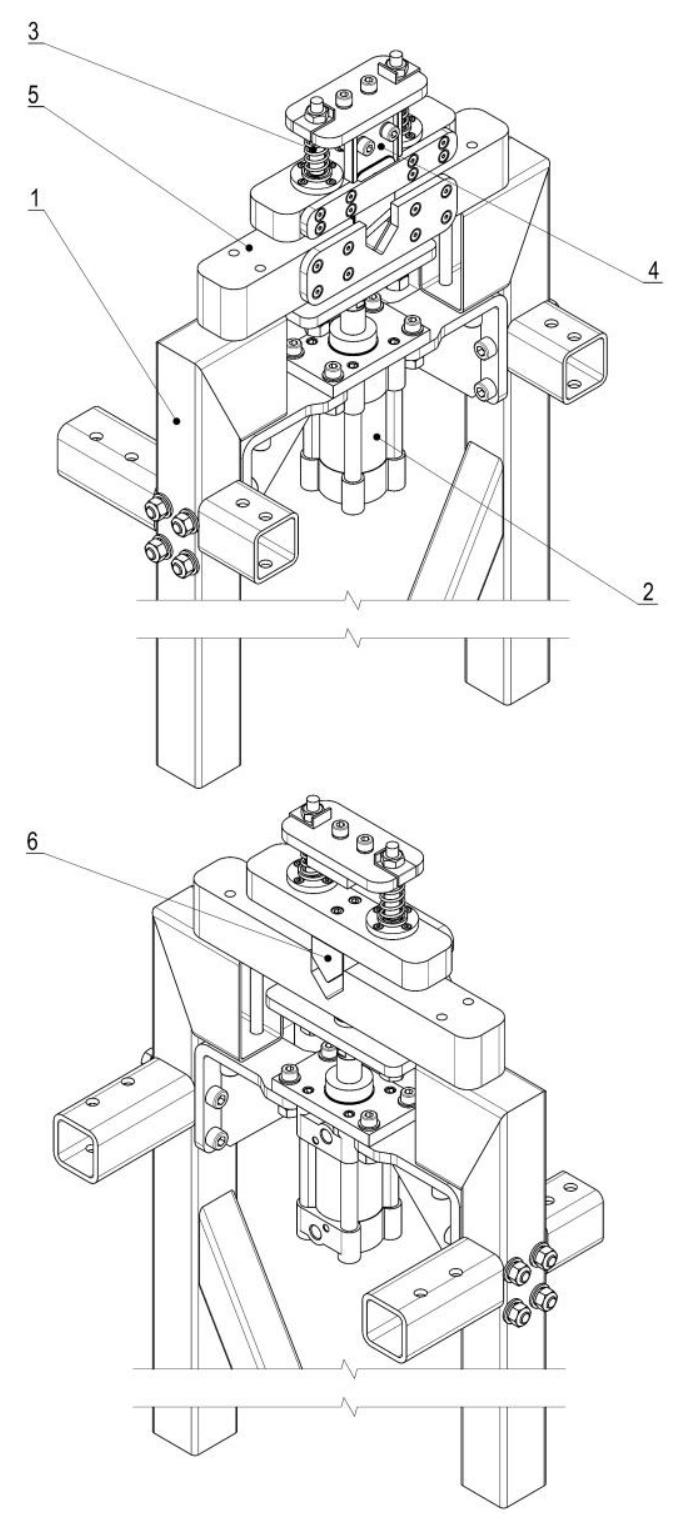

Fig. 12. Shear cutter assembly: 1 - frame, 2 - air cylinder, 3 - guide, 4 - cutting sub-assembly, 5 - die, 6 - hold-down device

The fixed gripper assembly rotates to turn the cord end about its axis and positions it in space. The rotational movement in the range from $0^{\circ}$ to $180^{\circ}$ is effect by the drive system (1) comprising the servomotor and the angular reduction gear bolted to the base plate (2). It delivers the torque to the bushing (4) fixed to the gripper base plate. The two plates (2 and 3 ) make up the supporting structure of the assembly, bolted to the shear cutter main frame ((1) in Fig. 12). The bushing is used to support the sectional lower jaw (5) whose shape enables grabbing and guiding the cord during movement. It operates in conjunction with the sliding top jaw (6) which is also shaped to grab the cord. The top jaw is fixed to the yoke (7) connected with the carrier of translational drive system (8) which effects its vertical movement. This sub-assembly comprises a stepper motor and a ball screw mounted through auxiliary frame (9) to the base plate (2). In this arrangement the gripper jaws close up, grabbing and securing the cord in position between the prismatic surfaces of the jaws. 


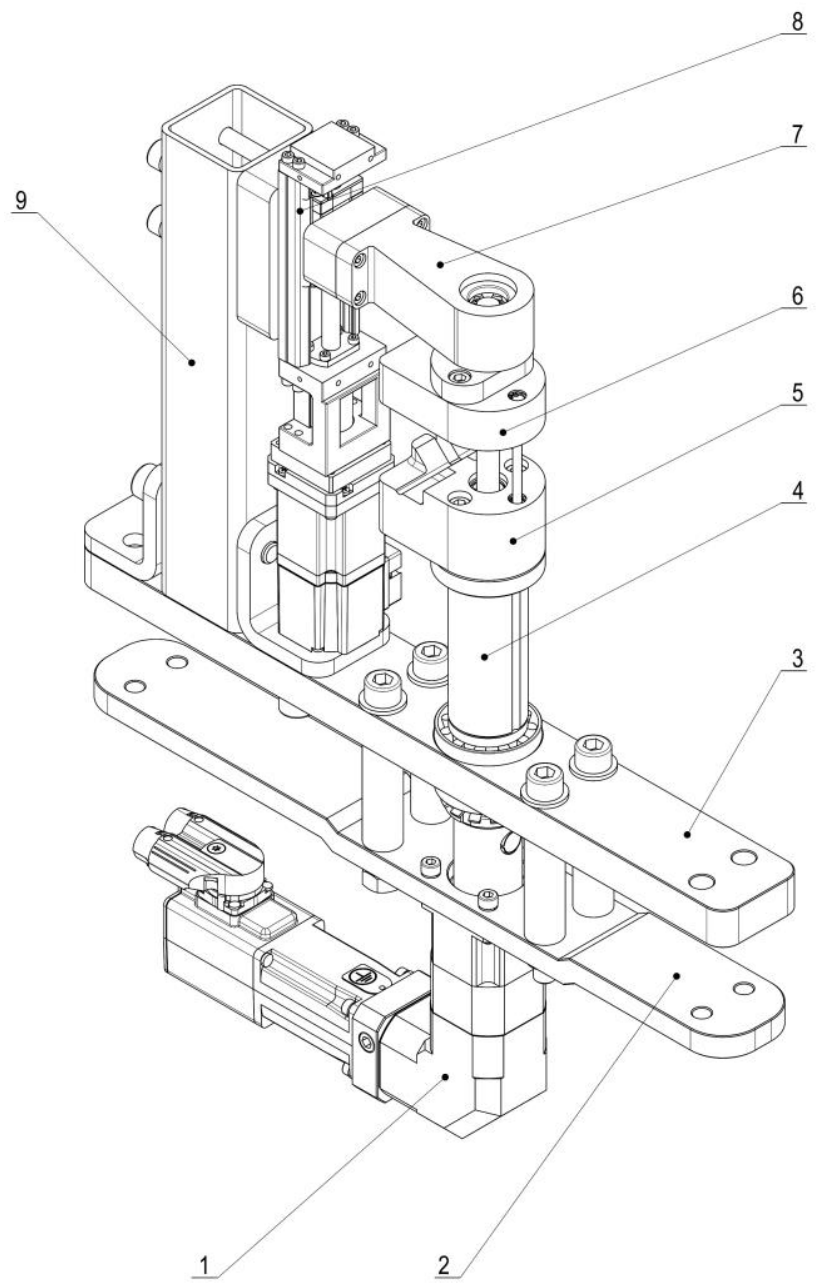

Fig. 13. Fixed gripper assembly: 1 - rotational movement drive system, 2 - drive system mounting plate, 3 - gripper system mounting plate, 4 - rotating bushing, 5 - lower jaw, 6 - sliding top jaw, 7 - yoke of the top jaw, 8 - translational closing movement drive system, 9 - auxiliary frame

- the function of the sliding gripper assembly (Fig. 14) is to grab and position the other end of the cord section.

The design and principle of operation of the cord end grabbing and turning system is similar to that of the fixed gripper assembly. The differences are limited to some design details concerning mounting of the servomotor (10), reduction gear (9), stepper motor powered gripper rotation drive system (12), gripper ball screw (11) and top jaw yoke (13). Notwithstanding the above differences the principle of operation remains the same.

The assembly is mounted through the base plates of the gripper (7) and the drive system (8) on the sliding frame (5) guided by the ball screw guides (6). This arrangement enables translational movement along the cord axis. The translational movement is effected by the stepper motor (3) through the ball screw drive (4). It is fixed to the frame through the bracket (8). For rigid construction, the translation movement drive system $(8,11$ and 12) and translation movement guides (6) are fixed to the frame (1) which in turn is mounted on the main frame of the machine ((1) in Fig. 9).

Worthwhile noting is the design of sliding the gripper assembly whereby the cord end grabbing and turning mechanism together with the drive systems can be moved along the cord axis to accommodate cord sections of infinitely variable length. Moreover, this feature enables pressing the ends of the cord section against each other in the subsequent steps of the splicing process and is used to remove the welding bead.

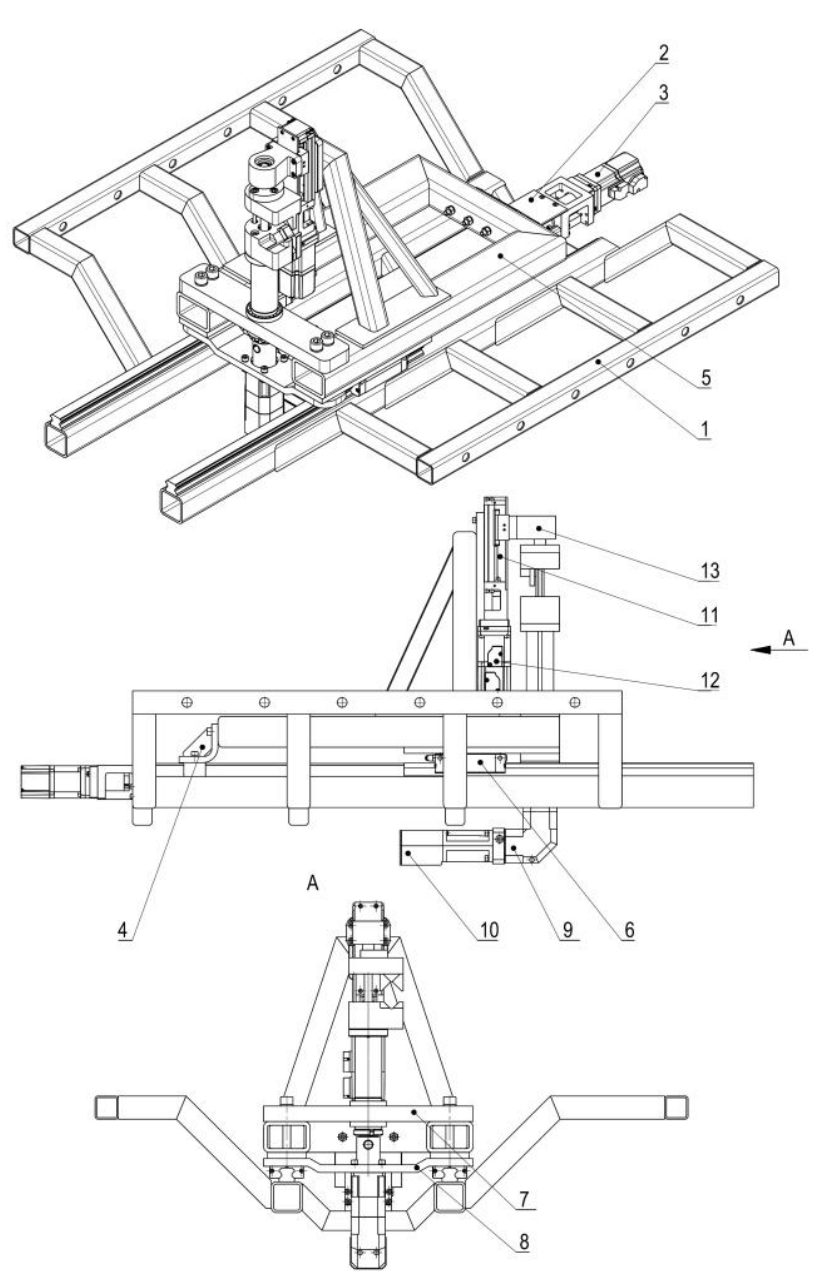

Fig. 14. Sliding gripper assembly: 1 - main frame of the gripper assembly, 2 - translational motion drive system, 3 - translational motion stepper motor, 4 - sliding frame bracket, 5 - sliding frame, 6 - linear guide, 7 - gripper base plate, 8 - rotational drive base plate, 9 - gripper rotation angular gear, 10 - gripper rotation servomotor, 11 - gripper closure ball screw, 12 - gripper closer ball screw, 13 - top jaw yoke

- the heater assembly (Fig. 15) is the most important assembly of the machine described in this paper. Its function is to supply sufficient amount of energy to the ends of the cord section, position the ends during welding and remove the welding bead.

The main frame (1) supports the horizontal guide plates (2) which, in turn, provide support for carriers (3). They operate in conjunction with the profile rails (4) bolted to the main frame of the machine ((1) in Fig. 9). This mechanism enables lateral movement of the whole assembly in the direction parallel to the cord axis. This arrangement ensures equal force with which the two ends are pressed against the heater and is used during the welding bead removal operation. The welding table vertical movement mechanism is also supported on the main frame of the machine (1). This sub-assembly comprises an auxiliary frame (5) used to support the ball screw drive (6) powered by the stepper motor (7). Through the bracket (8) the ball screw drive (6) is fixed to the 
frame (9) of the sliding welding table. The carriers of the translational movement guides (11) are fixed to the ball screw drive through brackets (10) and the guides are coupled with profiled rails (12) bolted to the frame (1). This mechanism enables vertical movement of the welding table to eliminate collision with grippers during positioning of the cord section before welding.

The welding table is delimited by the area on top of the frame (9) and is built of the following main sub-assemblies: left-hand die assembly (13) and right-hand die assembly (14) with heater installation (15). These sub-assemblies are equipped with appropriate mechanisms to effect the working movements (Fig. 16).

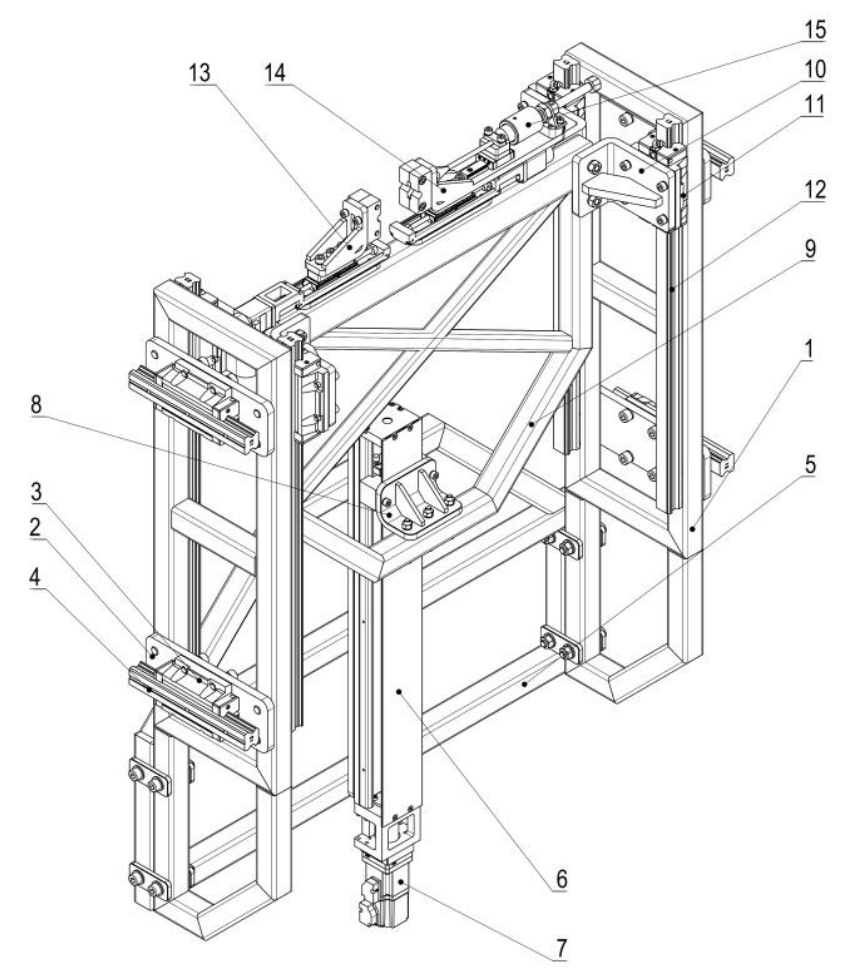

Fig. 15. Heater assembly: 1 - main frame, 2 - horizontal guide plate, 3 - translational movement guide carrier, 4 - guide rail, 5 - auxiliary frame, 6 - vertical movement drive system, 7 - vertical movement stepper motor, 8 - welding table bracket, 9 - welding table frame, 10 - vertical guide bracket, 11 - vertical guide carrier, 12 - vertical guide rail, 13 - left-hand die sub-assembly, 14 - left-hand die sub-assembly, 15 - heater

The base plates (2) of translational movement drive module (3), equipped with ball screw drives with additional guides and limit switches are bolted to the main frame (1). They are driven by stepper motors (4). The left-hand (5) and right-hand (8) die brackets are bolted to their carriers. The bracket support the two dies: cutting die (6) and guiding die (7). Thus the dies can come closer together, closing the ends of cord section within the cylindrical grooves.

The right-hand die bracket (8) supports the profiled rail (14) of the heater guide (9). It moves in conjunction with the guide carrier (13) supporting the heater (9) bolted to it through the yoke (12). The working surface is a flat heat platen with a non-stick coating. This element is inserted in the welding area, i.e. rectangular grooves in the dies due to the action of double-acting air cylinder (10). The cylinder is fixed to the die bracket (8) through the yoke (11). This design enables movement of the heater (9). It can be inserted between the cord ends, closed in the dies ( 6 and 7$)$ such that the heat platen entirely abuts the end faces.
- the main frame (Fig. 17) defines the spatial arrangement of all the machine assemblies.

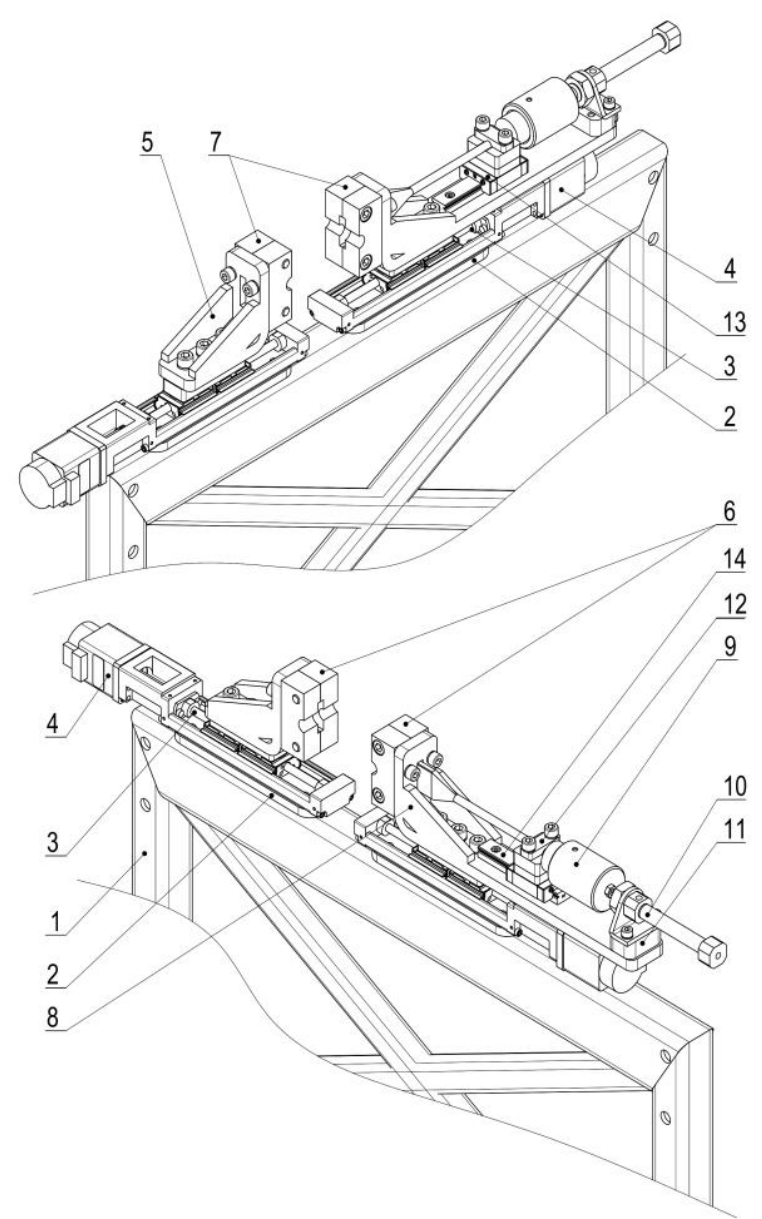

Fig. 16. Welding table: 1 - frame, 2 - base plate of translational movement drive, 3 - translational die movement drive system, 4 - stepper motor, 5 - left-hand die bracket, 6 - cutter die, 7 - guide die, 8 - right-hand die bracket, 9 - heater, 10 - air cylinder, 11 - air cylinder yoke, 12 - heater yoke, 13 - heater translation guide carrier, 14 - profiled rail of the heater translation guide

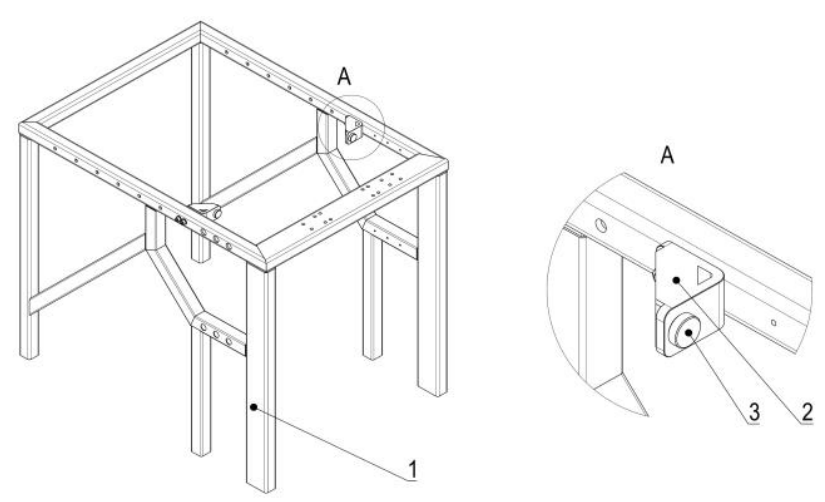

Fig. 17. Main frame: 1 - frame, 2 - end stop bracket, 3 - elastomeric end stop

The frame (2) is welded from steel sections. An important part of the assembly is the end stop (3) fixed to the frame through the ends top bracket (2). Its function is to restrict the range of movement of the heater assembly in the direction parallel to the cord axis during bead removal operation. 
The machine has a complicated structure. Moreover, the work area is small, this resulting from the small minimum length of belt $(150 \mathrm{~mm})$ to be handled. This makes the fabrication and assembly precision so important for all the sub-assemblies and parts of the machine.

\subsection{Control system}

The kinematic diagram of the machine (Fig. 18) enables preparation of the machine flow chart. This flowchart is then used to prepare the control system diagram. To avoid confusion it has been decided that the positive direction of translation corresponds to the positive direction of the adopted system of coordinates. For rotational movement the clockwise direction is positive.

As a preparation before starting the machine the spool with cord is placed on the unwind unit shaft (2). Next the cord is pulled from the spool and inserted between the feed rolls (3) through bushing with hole, mounted in the guide plate. This is possible due to free movement of the unwind unit in the $X Y\left(c_{1}\right)$ plane. Now adjustments should be done, which must be repeated after each replacement of the spool. Adjustments should cover also the unwind unit (2) and the roller feeder hold-down device (3). This ends the start-up preparations.

Next the operator makes sure that all the mechanisms are in their home positions that is:

- the shear cutter blade (4) is in the top end position, according to the positive direction of movement along axis $Y\left(y_{1}\right)$,

- fixed gripper (5) is in the end position in the positive direction of rotational movement in $X Z\left(b_{1}\right)$ plane. The opening made by the prismatic surfaces of the gripper jaws must be aligned with the shear cutter exit hole. Additionally the top jaw must be lifted up to the top end position of the movement along the $Y\left(y_{2}\right)$ axis.

- the sliding gripper (6) is in the right end position of movement in the positive direction along the $X\left(x_{1}\right)$ axis. Additionally, the gripper should be turned to the end position of the negative rotational movement direction in $\mathrm{XZ}\left(\mathrm{b}_{2}\right)$ plane and its jaw must be lifted to the top end position of movement in the direction along the $Y\left(y_{3}\right)$ axis,

- the welding assembly (7) is in the lower end position of movement in the direction along the $\mathrm{Y}\left(\mathrm{y}_{4}\right)$ axis and the dies are completely opened by movements in the positive $\left(z_{1}\right)$ and negative directions $\left(z_{2}\right)$ along the $Z$ axis. The heater must be removed from the die area to the end position of movement in the negative direction along $\mathrm{Z}\left(\mathrm{Z}_{3}\right)$ axis.

The machine can now start in automatic mode. The powered roll of the roll feeder (3) rotates in the in the negative direction of rotational movement in $X Y\left(c_{2}\right)$ plane. The cord end moves through the open jaws of the fixed gripper (5) until it reaches the sliding gripper (6). After passing the sliding gripper (so that some portion of the cord extends beyond the element face) the feeder drive system (3) stops without engaging the electromagnetic brake of the servomotor. Now the sliding gripper jaws are closed ((6), movement in the negative direction along axis $\left.Y-y_{3}\right)$, the cord is gripped and the jaws drive system is stopped to maintain the grip. Then the assembly pulls the cord from the unwind unit (2) while moving in the negative direction along the $X\left(x_{1}\right)$ axis. The length of the gripper movement depends on the specified belting length. At that point the roll feeder (3) can be restarted (3) to move the belt through open sliding gripper (5) thus increas- ing its quantity. This quantity is temporarily held between the grippers. When sufficient amount of the cord has been fed the feeder is stopped and the servomotor brake is engaged.
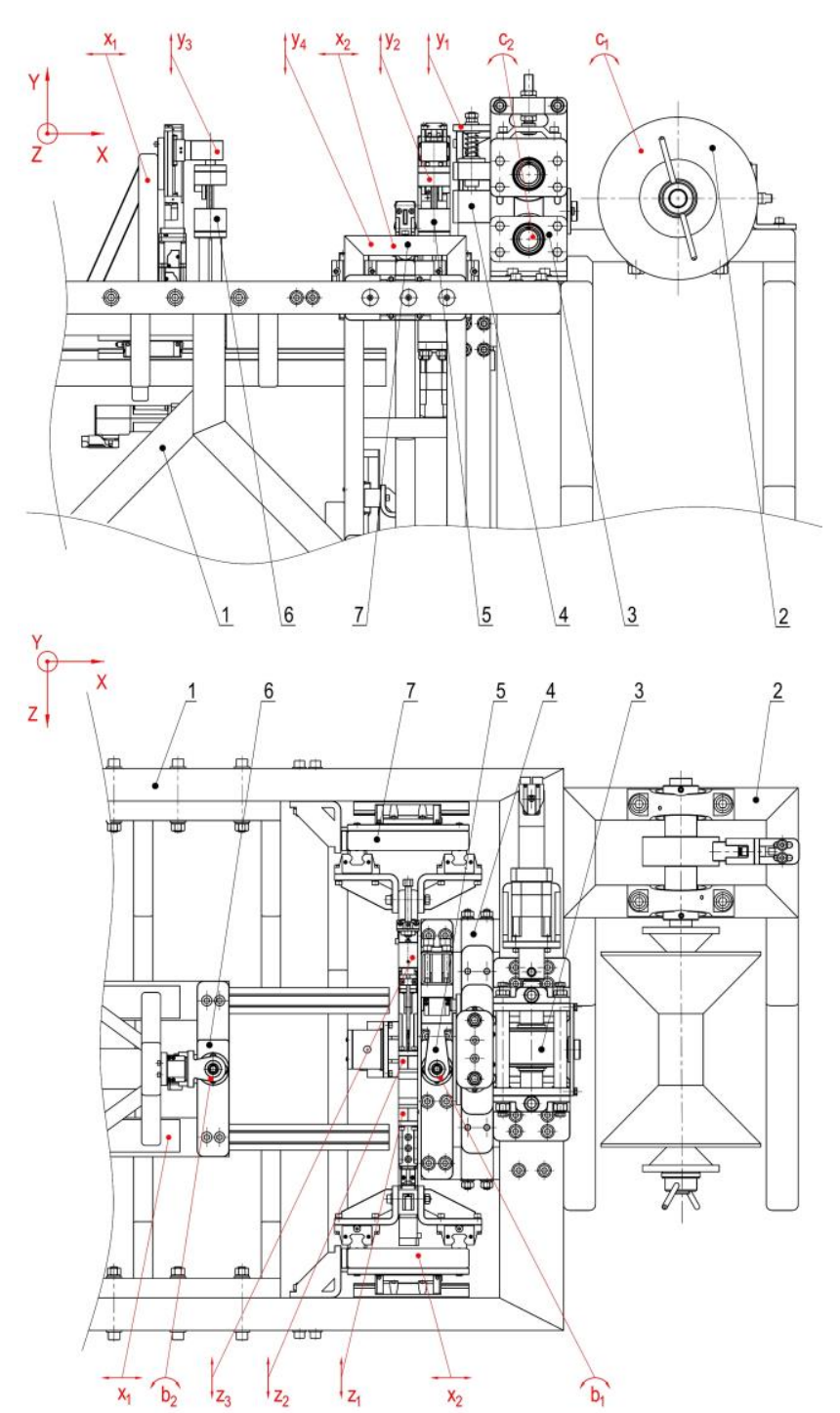

Fig. 18. Kinematic diagram of machine: 1 - main frame, 2 - unwind unit, 3 - roll feeder, 4 - shear cutter, 5 - fixed gripper, 6 - sliding gripper, 7 - welding assembly; Parameters: $x_{n}-$ translation in the direction of axis $X, y_{n}$ - translation in the direction of axis $Y$, $Z_{n}-$ translation in the direction of axis $Z, b_{n}$ - rotation in $X Z$ plane, $c_{n}$ - rotation in the $Y Z$ plane

Then the fixed gripper (5) closes by movement of the jaws in the negative direction along the $Y\left(y_{2}\right)$ axis. As previously, when the cord is gripped the jaws translational movement drive is controlled to stop in order to maintain the grip. At that point both ends are secured in position and against axial movement.

The next operation is cutting of the cord by the shear cutter assembly (4), involving movement of the cutter together with holddown device in the negative direction along the $Y\left(y_{1}\right)$ axis. Next the sliding gripper (6) moves in the positive direction along the $X\left(x_{1}\right)$ axis. During this movement the cord ends are initially positioned in relation to each other by rotation of the gripper jaws in the $\mathrm{YZ}$ plane by $180^{\circ}\left(\mathrm{b}_{1}\right.$ and $\left.\mathrm{b}_{2}\right)$ in opposite directions. This positions the cord end faces facing each other. On completion of this operation the rotational movement drives are stopped and 
their brakes are engaged. Next the sliding gripper is moved along the $X\left(x_{1}\right)$ axis to the preset position. The position results from the welding table width and is set at the value preventing collision of the machine assemblies.

Next the heater assembly (7) moves up along the $Y\left(y_{4}\right)$ axis to the position at which the holes in the dies are aligned with the belt ends. Then the vertical movement drive system is controlled to stop. The dies move along the $Z$ axis ( $z_{1}$ and $\left.z_{2}\right)$ until they come in contact, as detected by the limit switches installed on their ball screw drives.

When the cord ends are closed between the dies the heater is inserted between them moving in positive direction along the $Z\left(Z_{3}\right)$ axis, powered by air cylinder. Then the sliding gripper (6) moves in the positive direction along the $X\left(x_{1}\right)$ axis in order to press both surfaces against the heat platen. To ensure that the same pressure is applied on both side of the heat platen the whole heater unit $(7)$ is able move along the $X\left(x_{2}\right)$ axis. This movement is not limited by any external control. The cord end mounted in the sliding gripper (6) pushes through the heater the entire heater assembly, thus pressing the heat platen against the cord end that is being held in the fixed gripper (5).

Then the heating up phase follows, resulting in softening and partial melting of the cord end faces. In this phase the pressure can be adjusted by slightly moving the sliding gripper (6) along the $X\left(x_{1}\right)$ axis.

Next the sliding gripper assembly (6) is moved in negative direction along the $X\left(x_{1}\right)$ axis thus moving the end faces away from the heat platen. This enables withdrawing of the heat platen from the welding area (movement in negative direction along $Z$ axis $z_{2}$ ). Next the heated up ends of belting are pressed against each other by movement of the sliding gripper (7). Axial alignment of the end faces is ensured by alignment of the die holes through which the two ends pass.

After some time, sufficient for the seam to cool off the welding bead is removed. The process is effected by opening the fixed gripper (5) and then the sliding gripper (6) pulls the belt through the die. Initially the die moves together with the whole heater assembly (7) in the negative direction along the $\mathrm{X}\left(\mathrm{x}_{2}\right)$ axis until it rests against the end stops fixed to the main frame (1). Moving further the sliding gripper (6) pulls the belt through profiled hole of the cutting die, thus cutting off excess material.

After that the heating dies are withdrawn to their initial positions and the sliding gripper opens. Now the finished belt can be removed from the machine by the operator. All the mechanisms return to their home positions in a way to avoid collisions.

The key aspect to ensure the desired operation are the electrical settings of the control system (Fig. 19). Besides quality of welding it ensures effectiveness and safety of the machine operation.

The main element of this control system is programmable logic controller (PLC) which has the watchdog function. The PLC is equipped with the communication module (MK) to support networking with other controlling or operating devices via RS485 serial interface. One of the networked elements is the humanmachine interface providing the operating with status data (including number of completed belts) and information on the changes to the settings (such as heating up time).

The three drive units use AC servomotors (M1 - feeder drive system, M2 - fixed gripper rotation drive system and M3 - sliding gripper drive system). These units are controlled by dedicated controllers S1-S3 as they cannot be operated directly by PLC (Sreejeth et al., 2012). They control the operation of the AC ser- vomotor, the electromagnetic brake and also the digital encoder. In order to obtain a consistent control cycle the controllers are connected with the PLC, HMI, between themselves and with other elements via the RS485 interface. Master/slave relationship is established between PLC and the servomotor controllers with the PLC acting as master. The devices are supplied with $230 \mathrm{~V}$ power and in addition to their main function they deliver power to servomotors.

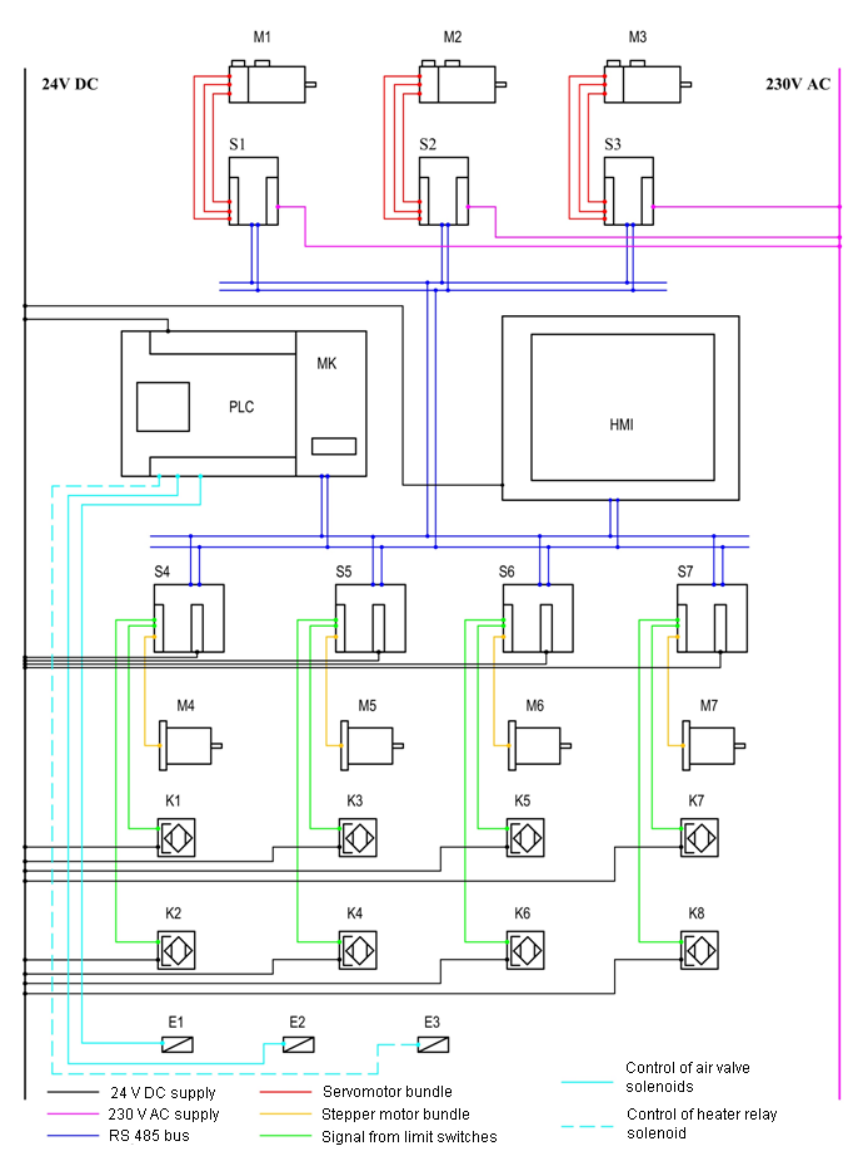

Fig. 19. Control system schematic: M1 - roll feeder servomotor, M2 - fixed gripper servomotor, M3 - sliding gripper servomotor, S1 - S3 - servomotor controller, PLC - central processing unit, MK - PLC communication module, $\mathrm{HMI}$ - human-machine interface, M4 - sliding gripper movement stepper motor, M5 - welding table lifting motor, M6 i M7- heating die movement stepper motor, S4 - S7 - stepper motor controller, K1 and K2 gripper end-of-travel limit switch, K3 and K4 - welding table lifting limit switch, K5 - K8 heating dies end-of-travel limit switch, E1 - solenoid of shear cutter cylinder valve , E2 - solenoid of the heater cylinder valve, E3 - heater relay solenoid

The remaining electrical drive systems are based on bipolar, two-phase stepper motors (M4 - M7) powering the ball screw drives, equipped with end-of-travel limit switches (K1 - K8). The drive systems based on M6 and M7 motors (drives of the heating dies elements) are identical while the systems driving the fixed gripper and lifting the welding table (M4 and M5 respectively) have higher power, higher maximum allowable forces and different dimensions. Characteristics of stepper motor - maximum torque from start, and mild decline with increasing of rotational speed are matched to work specification of i.e. sliding gripper. (Kukla et al., 2016). The maximum torque is required to i.e. remove waste from welding process by move of the gripper. 
The stepper motor cannot be controlled directly by PLC. Special controllers (S4 - S7) have been used to meet the control requirements. These devices are supplied with $24 \mathrm{~V}$ power and while controlling the stepper motors they also transmit power. The system functionality is maintained owing to connecting the stepper motor controllers to RS485 interface in order to enable communication with the master controller (PLC) in master/slave configuration.

The reed limit switches $(\mathrm{K} 1-\mathrm{K} 8)$ protect the drive systems from losing steps by the stepper motors.

The solenoid (E1) operates the spring return pneumatic valve $5 / 2$ through which air is supplied to the shear cutter cylinder. The solenoid (E2) operates the valve supplying air to the heater cylinder. Activating both solenoids produces operating movements of the sub-assemblies connected with the respective cylinders and when they are disconnected the sub-assemblies return to their home positions. The solenoid (E3) activates the heater when the machine is starting up. With fixed working temperature of $200^{\circ} \mathrm{C}$ it can be controlled by the solenoid alone. All the solenoids are controlled directly from binary outputs of the PLC.

The control system design is based on commercially available devices.

\section{CONCLUSIONS}

Application of mechatronic design methods in designing industrial machine systems can lead to automation of various manual processes. Thus these processes can be carried out without operator's involvement. One of such processes is butt welding of round belting. The process is generally done by hand. Automation of the process requires designing a machine to perform all the operations of the process flow chart. The mechatronic assemblies are expected to improve the effectiveness of welding while ensuring satisfactory quality of the finished products.

There are several important factors to be taken into account in the design and implementation of the machines for automatic splicing of belting. The mechanical part of the machine must enable processing cords of specified geometry. It is also necessary to define the size range of finished products to be handled by the machine which will significantly influence the dimensions of the machine sub-assemblies. The control system must, on its part, execute the process flow chart that is quite complex in this case. Appropriately designed control is critical for good quality of welding. Communication with operator is also important. It is necessary to enable monitoring and adjustment of the current parameters, such as finished belt length. Last but not least, one should remember about safety of operation. It is important to protect both the machine and the people in its vicinity from unplanned situations associated with the characteristics of the processed material, such as uncontrolled unwinding of cord from the spool.

The design of the mechanical, as well as control systems of the machine, as described in this paper provides the basis for building a prototype of the designed machine. Whether or not any modifications should be implemented in the proposed design should be established on the basis of experimental verification of the machine functions and of the quality of splicing.

\section{REFERENCES}

1. Amanat N., James N. L., McKenzie D.R. (2010), Welding methods for joining thermoplastic polymers for the hermetic enclosure of medical devices, Medical engineering \& Physics, Vol. 32, 690-699.

2. Amancio-Filho S.T., dos Santos J.F. (2009), Joining of Polymers and Polymer-Metal Hybrid Structures: Recent Developments and Trends, Polymer Engineering and Science, 49(8), 1461-1476.

3. Ashby M.F., Jones D.R.H. (1996), Engineering materials (in Polish), WNT, Warszawa.

4. Behabelt (2015), Product Catalogue 2015/2016, Behabelt, Glottertal.

5. Casalino G., Ghorbel E. (2008), Numerical model of $\mathrm{CO}_{2}$ laser welding of thermoplastic polymers, Journal of Materials Processing Technology, 207, 63-71.

6. Ciszewski A., Radomski T. (1989), Construction materials in machine design (in Polish), PWN, Warszawa.

7. Cocard M., Grozav I., lacob M., Caneparu A. (2009), Establishing the Optimum Welding Procedure for PE 100 Polyethylene Pipelines Using the Response Surface Design, Materiale Plastice, 46(4), 452-457.

8. Domek G., Dudziak M. (2011), Energy Dissipation in Timing Belts Made From Composite Materials, Advanced Material Research, 189- 193, 4414-4418.

9. Domek G., Kołodziej A., Dudziak M., Woźniak T. (2016), Identification of the quality of timing belt pulleys, Procedia Engineering, 177, 275-280.

10. Domek G., Malujda I. (2007), Modeling of timing belt construction, Proceedings in Applied Mathematics and Mechanics, 7, 45-46.

11. Evers F., Schöppner V., Lakemeyer P. (2017), The influence on welding processes on the weld strength of flame-retardant materials, Weld World, 61, 161-170.

12. Inoue T., Miyata R., Hirai S. (2016), Antagonistically Twisted Round Belt Actuator System for Robotic Joints, Journal of Robotics and Mechatronics, 28(6), 842 - 853.

13. Jasiulek P. (2006), Joining of plastics by welding, glueing and laminating (in Polish), Wydawnictwo "KaBe", Krosno.

14. Klimpel A. (1999), Metals and thermoplastic polymers welding technology (in Polish), Wydawnictwo Politechniki Śląskiej, Gliwice.

15. Klimpel A. (2000), Welding of termoplastics materials (in Polish), Wydawnictwo Politechniki Śląskiej, Gliwice.

16. Kukla M., Tarkowski P., Malujda I., Talaśka K., Górecki J. (2016), Determination of the torque characteristics of a stepper motor, Procedia Engineering, 136, 375-379.

17. Madej M., Ozimina D. (2010), Plastics and composite materials (in Polish), Wydawnictwo Politechniki Świętokrzyskiej, Kielce.

18. Puszka A. (2006), Polyurethanes - sources, properties and modifications (in Polish), Zakład Chemii Polimerów, Wydział Chemii Uniwersytetu Marii Curie Skłodowskiej w Lublinie, Lublin.

19. Rzasinski R., (2017), The algorithm of verification of welding process for plastic pipes, IOP Conference Series: Materials Science and Engineering, 227, 012113.

20. Sikora R. (1993), Proceeding macromolecular materials (in Polish), Wydawnictwo ŻAK, Warszawa.

21. Sreejeth M., Singh M., Kumar P. (2012), Monitoring, Control and Power Quality Issues of PLC Controlled Three-Phase AC Servomotor Drive, 2012 IEEE Fifth Power India Conference, 19-22 Dec. 2012, Murthal, India.

22. Wanqing L., Changqing F., Xing Z., Youliang C., Rong Y., Donghong L. (2017), Morphology and thermal properties of polyurethane elastomer based on representative structural chain extenders, Thermochimica Acta, 653, 116-125.

23. Yousepour A., Hojjari M., Immarigeon J-P. (2004), Fusion Bonding/Welding of Thermoplastic Composites, Journal of Thermoplastic Composite Materials, 17, 303-341.

24. Żuchowska D. (2000), Construction polymers (in Polish), WNT, Warszawa. 